\title{
How do voters choose one out of many? The effect of endorsements on candidate choice
}

\author{
Henrik Serup Christensen, Åbo Akademi University \\ Theodora Järvi, University of Helsinki \\ Mikko Mattila, University of Helsinki \\ Åsa von Schoultz, University of Helsinki
}

Preprint date: 2 November 2020

\begin{abstract}
Candidate endorsements are known to affect the likelihood that a voter will vote for a candidate since they reduce the efforts devoted to vote choices. However, the effects of endorsements from different sources remain under-explored. Furthermore, the effects of endorsements are believed to vary with the level of political sophistication, as voters with low sophistication are more reliant on such shortcuts, but it is unclear whether these differences are similar for different sources. We study the effects of endorsements from three different sources - family and close friends, networks on social media and Voting Advice Applications (VAAs) - on candidate favorability. We do so with a choice-based conjoint experiment embedded in a survey from Finland ( $n=1021)$, where we also examine differences in effects across political sophistication (political interest, frequency of political discussions, internal political efficacy, party identification, and voting in the last parliamentary election). The results show that endorsements from VAAs and family and friends have positive effects while social media networks do not. We do not find systematic differences in effects across levels of political sophistication no matter how we operationalize it. This shows that it is important to consider the source of an endorsement to appreciate the effect, no matter who is the recipient.
\end{abstract}

Key words: Endorsements; Voting Advice Applications; Candidate choice; Political sophistication; Conjoint analysis 


\section{Introduction}

During election campaigns, voters are confronted with an overflow of campaign messages, and rather than basing their decisions on all available information, they tend to apply various information shortcuts that allow them to reduce the transactional costs involved in gathering relevant political information, and help them make an (informed) vote choice. Previous research has established that voters use information shortcuts, such as party labels (Huddy et al., 2018), descriptive characteristics, such as gender and age (Holli and Wass, 2010; Banducci and Karp, 2000), impressions of personality (Ambady and Rosenthal, 1992; Benjamin and Shapiro, 2009) or previous experiences (Cox and Katz, 1996; Feld and Grofman, 1991) of candidates, and the likeliness of the candidate winning a seat (Gschwend et al., 2004).

An alternative shortcut to a voting decision is to rely on endorsements from various sources; the relative impact of which is the focus of this study. Endorsements of a specific party or candidate can ostensibly provide a strong information heuristic provided they come from a source that the recipient finds credible. The literature on social networks informs us that guidance from close social contacts, such as close family relations, can have an impact on vote choices across electoral contexts (Santoro and Beck, 2017). In fact, face-to-face interaction has, since the pioneer studies on voting behavior, been considered as the most important stimulation of opinion change (Eulau, 1980). This line of literature has also found that input from other, broader social networks can influence vote choices; networks that in today's digitalized world to a large extent are played out at various social media platforms (Sinclair, 2012).

In modern election campaigns, voting advice in the shape of an endorsement, do however not only come from social contacts and networks. Increasingly popular tools in many countries, designed to assist citizens with their vote choices, are Voting Advice Applications (VAAs). VAAs are online tools that match political preferences of the individual voter on a large amount of policy issues, with that 
of parties or individual candidates running for office (Garzia and Marschall, 2019). As such, they are fundamentally heuristic-generating instruments, creating an output for the users that can be considered as equivalent to that of an endorsement (Wall et al., 2014). A potentially very persuasive element of VAAs, and one that makes it stand out compared to other types of endorsements, is that the output these applications produce is a tailor-made recommendation for vote choice, directly reflecting the user's own opinions. The growing research on VAAs has demonstrated that these tools are particularly popular in multiparty systems, and that they can influence voters' behaviors in multiple ways (for a review see Trechsel and Garzia, 2019).

In this study we are interested in studying the effect of different types of endorsements on candidate choice, departing from the assumption that not all endorsements carry the same weight in voters' decision-making process. We also consider previous research showing that political sophistication and motivation affect the use of information shortcuts (Milic, 2020; Bernard and Freeder, 2020). Sophisticated voters, who are more interested in politics, are likely to engage in a broader and more detailed decision-making process than less sophisticated, which means that sophisticated voters are less likely to rely only on simple information heuristics (Singh and Roy, 2014). Hence, we assume that less sophisticated voters are particularly responsive to endorsements since they are more likely to be low on information and therefore in greater need of guidance or effective shortcuts.

Our study focuses on the effect of different types of endorsements on candidate choice and makes four main contributions to existing research. First, previous studies have investigated the impact of endorsements on electoral choices (Santoro and Beck, 2017; Kleinnijenhuis et al., 2017) but since they focused on different types of endorsements in isolation, it remains unclear what kind of endorsements are more important for influencing perceptions of candidates. Second, our analyses 
examine the importance of endorsements for candidate favorability compared to other types of information, such as candidates' ideological positions, social characteristics, and their previous political experience. Third, we examine how the effects of endorsements vary across levels of political sophistication, which is important as previous research show that less sophisticated voters are more prone to apply easily available information that demands less effort in terms of information processing (Popkin and Dimock, 1999).

Our fourth contribution is related to the methodology we use. We examine the impact of endorsements on candidate favorability with a choice-based conjoint experiment. This method has important advantages compared to the alternatives, since it allows us to examine the causal effects of multiple traits on candidate favorability (Franchino and Zucchini, 2015), reduce problems with social desirability bias, and approximate real-life effects (Hainmueller et al., 2015). This conjoint analysis is embedded in a representative Finnish survey $(n=1021)$ carried out in spring 2020. Finland constitutes an interesting case for our study since it provides an electoral context with a high level of intraparty competition where voters are familiar with voting for a single candidate from a large pool of aspirants (von Schoultz, 2018). This means that the conjoint framework involving a choice between candidates is familiar to respondents, and we can therefore expect voters to rely on similar strategies as in real elections.

We find that endorsements from family and close friends and VAAs affect candidate favorability, whereas endorsements from networks on social media do not seem to change candidate favorability. The effect sizes are in line with effects from candidate's socio-demographic background and political experience. Contrary to our expectations, the effects of endorsements do not systematically differ across respondents' level of political sophistication. This leads us to believe that 
endorsements in any form are unlikely to help to even out the differences between voters with different levels of political sophistication.

\section{Endorsements and candidate choice}

How do voters decide which candidate to cast their vote for? During modern election campaigns, voters are confronted with a myriad of information, and to keep track of all relevant campaign messages and to process all available facts on candidates and their policies takes a great deal of effort and time. While some of the early literature on vote choice (Downs, 1957) maintained that voters should have complete information to cast a correct or rational vote, abundant research has since concluded that a fully informed vote is rarely, if ever, reality. While studies show that voters are generally fairly ignorant of political processes (Dahl, 1989; Carpini and Keeter, 1996), and that they hold unstable (Converse, 1964) or ambivalent political opinions (Zaller, 1992; see however Nord $\varnothing, 2019$ ), this does not necessarily lead to uninformed vote choices (although see Bartels, 1996). A great deal of literature maintains that voters use various cues or heuristics that allow uninformed voters to make choices as if they were informed (Berelson et al., 1954; Neuman, 1986; Page and Shapiro, 1992).

To minimize the cognitive effort of information retrieval, voters often resort to information shortcuts (Downs, 1957; Cox and Katz, 1996; Feld and Grofman, 1991). Such strategies increase voters' cognitive efficiency and help them to overcome limitations in information processing and lack of political knowledge (Lau and Redlawsk, 2006), and reduce the time and effort devoted to deciding how to vote. Information shortcuts come in different forms and can be, for example, related to the ideological schemata of politics, perhaps in the form of party identification (Conover and Feldman, 1986), or to specific policy issues (Arnesen et al., 2019). They can, however, also be less related to the substantive side of politics, and instead connect to various characteristics of 
candidates such as their age, gender or looks (Campbell and Cowley, 2014; Pedersen et al., 2019; Berggren et al., 2010).

In this study, we are particularly interested in the role of direct guidance or advice in relation to vote choices, i.e., we study endorsement heuristics (Lau and Redlawsk, 2006), and the relative impact of different types of endorsements on the choices voters make.

Some of the most easily accessible pieces of political information come from social networks like friends and family. Accordingly, research has demonstrated that voters are influenced by the messages they receive from their social contexts (Beck et al., 2002). While effects of the close social context on voting behavior generally works through slow socialization processes, where voters absorb cues over time (McPhee, 1963), endorsements from family or close friends can also provide direct guidance on which candidate to vote for in specific elections.

The role of social networks has changed substantially with the rise of the internet and social media. While most social interactions and peer discussions of political issues before social media involved face to face-interactions, today interactions largely take place on online media platforms like Facebook or Twitter (Aldrich et al., 2016; Beck et al., 2002). Research on the impact of social media networks often presume that social endorsements on these platforms are perceived as useful since people "assume that the support of others is likely to predict personal relevance and utility" (Messing and Westwood, 2014, 1047; Sundar and Nass, 2001). Research has shown that social media endorsements impact various types of behaviors such as news consumption (KnoblochWesterwick et al., 2005; Lerman, 2007; Messing \& Westwood, 2014), music consumption (Salganik et al., 2006), and course preferences among college students (Steffes and Burgee, 2009). While research on the role of social media networks on political behavior has grown in popularity, it appears to a large extent to focus on mobilizing effects and turnout (Bond et al., 2012; 2017), leaving 
the impact of social media on vote choices relatively unexplored (Santoro and Beck, 2017; see however Ohme et al., 2017).

Another increasingly popular source for guidance in vote choices is Voting Advice Applications (VAAs). VAAs are online tools designed to match voters with specific parties or candidates based on answers to a set of questions on specific policy issues (Garzia and Marschall, 2019). After having compared the answers of the individual user with the those provided by individual candidates or by parties, the VAA generally produces a rank-ordered list indicating which candidates (or parties) are the most proximate to the voter. VAAs hence function as heuristic-generating instruments, and the created output is equivalent to that of an endorsement (Wall et al., 2014). Compared to other types of endorsements based on personalized contacts or spread via social media networks, the output derived from VAAs is unique in the sense that it provides a personalized and tailor-made advice, based on the comparison of the issue stands of the individual voter and nominated candidates (Trechsel and Garzia, 2019).

In information-rich electoral contexts with many parties or candidates at display, VAAs offers a valuable low-cost option for gaining insight into candidates' ideological positions and they have become widely used in many countries (Garzia and Marschall, 2019). Research on VAAs has expanded substantially over the last decade. While many studies in the field rely on less ideal crosssectional and opt-in data, findings indicate that VAAs can influence political behavior in a variety of ways (Munzert and Ramirez Ruiz, 2020). VAA usage has for example been shown to mobilize voters (Gemenis and Rosema 2014; Garzia et al., 2017), to have positive cognitive effects (Kamone et al., 2015; Schultze, 2014), and to influence vote choices (Kleinnijenhuis et al., 2017). Considering the growing importance of VAAs, we include this in our study even if they strictly speaking are not social influences since their output reflects user's own opinions, rather than the opinions of a particular 
group or party. However, VAAs may rival the importance of social cues since they provide a persuasive tool that reduces the costs for a voter to engage in informed issue voting (Walgrave et al., 2008).

One of the main conclusions from research on social networks and how they influence vote choices is that close and strong social ties are more important than weak ones (Sinclair, 2012; Nowak et al., 1990). This is also in line with Latané's (1981) social impact theory which posits that the stronger the ties of the advice giver, and the more credibility (Nowak et al., 1990) that person holds, the more important the heuristic becomes. Generally, if the information giver is perceived to be knowledgeable and honest, the endorsement is seen as valuable, especially by less-informed voters (Lupia, 1994). Hence, voters often resort to the opinion of close relations, whose opinions they value and find credible (e.g. Sinclair, 2012). In other words, the closer the ties, the more credible the information received. In a similar manner, the immediate social context - the persons of confidence (like family and spouses) - have a noted impact on the vote choices (Beck, et.al, 2002). Therefore, it is important not only to follow whether endorsements serve as heuristics, but also which types of endorsements are held as most credible.

Based on these considerations, we propose the following hypotheses for the effects of endorsements on candidate favorability:

H1a: Endorsements have a positive effect on candidate favorability

$\mathrm{H} 1 \mathrm{~b}$ : The effect of endorsements on candidate favorability vary according to the strength of the social ties between the respondent and the source of the endorsement 
Voters are hence assumed to rely on endorsements heuristic, but the extent to which all voters are as susceptible to endorsements is less clear. To elaborate further the relationship between endorsements and different types of voters, we turn to the concept of political sophistication (see Rapeli, 2013, 12-16, for various definitions of the term). In general terms, this concept refers to levels of cognitive complexity of individuals' political thinking, i.e., their levels of political expertise (Luskin, 1990). On a more concrete level, sophistication is often considered to include such dimensions as interest in and attention to politics, party identification and political knowledge.

Previous studies show that individuals differ substantially in their attention to politics and exposure to sources of political information, and that their reactions to new political information are at least partly affected by their levels of political awareness or sophistication (Zaller, 1992). Due to more extensive knowledge of politics, politically sophisticated voters are considered better able to absorb the complexities of politics (Funk, 1997). Hence, there are reasons also to believe that voters' levels of political sophistication affect the way they use heuristics and cues to aid their candidate selection. For example, Sniderman et al. $(1991,119)$ noted in their study that: "It is [...] not plausible to suppose that the well-informed voter and the poorly informed one go about the business of making up their minds in the same way".

In line with this, previous research shows that politically sophisticated voters evaluate candidates and reach their candidate choice in different ways than voters with lower levels of political sophistication (e.g. Bartels, 1996; Dalton, 1984; Goren, 1997; Johns and Shephard, 2007; Popkin, 1991; Zaller, 1990; Singh and Roy, 2014). Popkin and Dimock (1999), for example found that people with less knowledge about the political institutions rely on different types of information when evaluating candidates, compared to those with more knowledge about the political system. Less sophisticated voters give higher priority to information related to personal characteristics than to 
substantive political issues, such as ideological positions or previous performance. Some studies have, in turn, pointed towards an asymmetric effect of political sophistication, with the effect mainly being played out in relation to complex information. Accordingly, voters with high levels of politically sophistication are more prone to rely on complex information, while easy heuristics, such as party affiliation and candidates' socio-demographic characteristics, are used to a similar degree across levels of political sophistication (Sniderman et al., 1991; Cutler, 2002; Kim, 2006; Coffé and von Schoultz, 2020).

Endorsements can be considered as easy heuristics. In fact, some of the most easily accessible information pieces regarding politics come from social networks like family and close friends that may potentially simplify the voting decision for citizens with less experience. Along these lines, research shows that social media platforms are more influential among young, less experienced voters, who find close friend's recommendations, or posts with high amounts of reads and reactions as credible (Ohme et al., 2018). A similar argument has been put forward for VAAs, considered particularly important for first-time voters who do not have so much experience with voting (Kristensen and Solhaug, 2017). It should however be noted that VAAs tend to attract politically interested and aware voters at high rates (Marschall, 2014), which might be explained by the strong focus on political issues on these platforms, and that they are considered as entertaining by political sophisticates.

While research on the effect of political sophistication is not fully univocal, we find it reasonable to argue that individuals with lower levels of political sophistication are affected to a greater extent by endorsements when making their choice.

This leads us to our final hypotheses:

H2: Endorsements have a stronger effect among respondents with less political sophistication 


\section{Research design}

To test our hypotheses, we rely on a conjoint experiment embedded in a representative sample of the Finnish population when it comes to age, gender, and region of living, as shown in the supplement file $(n=1021) .{ }^{1}$ The data was collected between 26 February 2020 to 4 March 2020 via an online panel recruited through Qualtrics. ${ }^{2}$

Finland constitutes an interesting case for examining candidate endorsement as the Finnish electoral system is a strongly candidate centered open list system (von Schoultz 2018). To cast a vote, voters need to identify a single candidate out of a wide selection of contenders. Despite the strong candidate focus in voters' electoral choices, Finnish politics resembles most other westernEuropean democracies in that it revolves around a fairly stable set of relevant parties, and that parties structure how politics is carried out. The system can hence be described as having two salient levels of competition; that between parties fighting for political power, and that between candidates, fighting to become a representative for a specific party. The latter level of competition often takes place between candidates nominated for the same party. Since voters need to select a candidate rather than vote for a party list, voters are accustomed to choosing between candidates, which serves to enhance the validity of conjoint analysis as a method to examine our hypotheses. Further, both social media platforms ${ }^{3}$ such as Facebook, Instagram and Twitter, and VAAs ${ }^{4}$ are widely used by Finnish citizens. By examining the Finnish context, we can increase the face validity

\footnotetext{
${ }^{1}$ Out of a concern for data quality, we excluded respondents who filled in the survey in less than 2 minutes and those who took more than 12 minutes to answer all questions. Since the sample resembles the general population, we do not employ weighting during the analyses.

${ }^{2}$ The study was preregistered at https://osf.io/k5gvn. When deviations from the plan occur, they are noted in the text.

3 According to statista 67 percent of all individuals used social networks in Finland in 2019 (https://www.statista.com/statistics/384465/social-network-penetration-in-finland/).

${ }^{4}$ The Finnish Public Broadcasting Company (YLE) introduced the first VAA in 1996, and other media actors were soon to follow. Voters have embraced the development, with close to half $(49 \%)$ of the electorate using at least one voting advice application during the 2019 parliamentary election campaign (Suomen virallinen tilasto, 2019). Finnish VAAs are generally candidate oriented, producing an outcome that match users' responses with those of individual candidates, without taking into consideration which party that has nominated the candidate.
} 
of the conjoint experiment, but the generalizability of the results outside of Finland and more party centered contexts remains uncertain.

While previous studies have examined similar questions, the use of conjoint analysis for studying the impact of endorsements provides advantages compared to research based on traditional survey items (Hainmueller et al., 2014). Conjoint analysis makes it possible to examine the effects of multiple traits on candidate choice (Franchino and Zucchini, 2015; Marx and Schumacher, 2018; Kirkland and Coppock, 2018; Breitenstein, 2019). Furthermore, since it is not necessary to ask respondents directly for their preferences on the given attributes, this technique minimizes problems with social desirability bias, which can present a challenge when examining attitudes and preferences in surveys (Ono and Yamada, 2018; Breitenstein, 2019). Conjoint experiments also approximate real-life effects and therefore minimize potential problems with external validity (Hainmueller et al., 2015).

We use a choice-based conjoint design, where respondents are asked to pick their favorite candidate from two profiles consisting of different values of seven attributes. The attributes and their possible values are shown in Table 1, while a screenshot of how the conjoint appeared in Qualtrics is included in the supplement file. ${ }^{5}$ Respondents were first presented with a short introduction that explained that the aim of the study was to examine candidate choice. Following this, they were presented with seven comparisons of two hypothetical candidates and asked to pick the one they would vote for in an election for the Finnish Parliament. ${ }^{6}$

\footnotetext{
${ }^{5} \mathrm{~A}$ rating-based conjoint allows respondents to rate candidates, but the choice-based approach is simpler, resembles the voting situation to a greater extent, and substantial results are in most cases similar (Hainmueller et al., 2014).

${ }^{6}$ We did not include a possibility to pick neither of the candidate profiles meaning respondents were forced to pick either of the alternatives on offer. It is therefore not possible for the respondent to express a lack of interest in the candidates on offer, which may sacrifice some of the realism of the experiment.
} 
Table 1. Conjoint attributes and levels

\begin{tabular}{|c|c|c|}
\hline Attribute & Description in conjoint & Levels (R=Reference category) \\
\hline 1 Endorsement & $\begin{array}{l}\text { The candidate has been endorsed } \\
\text { by }\end{array}$ & $\begin{array}{l}\text { No information }(\mathrm{R}) \\
\text { No endorsement } \\
\text { Voting Advice Applications } \\
\text { Network on social media } \\
\text { Family member or close friend }\end{array}$ \\
\hline 2. Gender & Gender of candidate & $\begin{array}{l}\text { No information }(\mathrm{R}) \\
\text { Male } \\
\text { Female }\end{array}$ \\
\hline 3. Age & Age of candidate & $\begin{array}{l}\text { No information () } \\
27 \\
44 \\
61\end{array}$ \\
\hline 4. Education & $\begin{array}{l}\text { The candidate's educational } \\
\text { background }\end{array}$ & $\begin{array}{l}\text { No information }(\mathrm{R}) \\
\text { Basic education } \\
\text { Intermediate education } \\
\text { University degree }\end{array}$ \\
\hline 5. Ideological proximity & The candidate's political position & $\begin{array}{l}\text { No information }(\mathrm{R}) \\
\text { Close to own political views } \\
\text { Far from own political views }\end{array}$ \\
\hline 6. Political experience & The candidate's political experience & $\begin{array}{l}\text { No information }(\mathrm{R}) \\
\text { No current office holding } \\
\text { Holds office in local council } \\
\text { Holds office in Eduskunta }\end{array}$ \\
\hline $\begin{array}{l}\text { 7. Chance of winning } \\
\text { seat }\end{array}$ & $\begin{array}{l}\text { The chance that the candidate will } \\
\text { win a seat is }\end{array}$ & $\begin{array}{l}\text { No information }(\mathrm{R}) \\
\text { Very likely } \\
\text { Intermediate } \\
\text { Very unlikely }\end{array}$ \\
\hline
\end{tabular}

For endorsements, we include four different alternatives in line with the theoretical discussion above. The first specifies that no one has endorsed the candidate. While this may resemble the no information category, the effect of knowing that no one endorsed the candidate may have a different effect on vote choice. Other than this, we include three types of endorsements: From Voting Advice Applications (VAAs), from social media networks, and from family or close friend. While we, in accordance with $\mathrm{H} 1 \mathrm{a}$, expect all types of endorsements to have positive effects, the effects, in accordance with $\mathrm{H} 1 \mathrm{~b}$, are expected to vary according to the strength of the social ties between the respondent and the source of the endorsement. We expect endorsements from networks on social media to have the weakest effect and endorsements from close friends and family to have the strongest effect. As already mentioned, the effect of VAAs is unclear in this connection, since it on one hand does not derive from specific social ties, but on the other hand 
match the voter's own issue positions with those of candidates, which could provide a strong effect on candidate choice.

As concerns the other attributes, gender entails a distinction between male and female candidates. For age, we offer three alternative ages in years separated by 17 years: 27 , describing a young candidate; 44, describing a middle-aged candidate $^{7}$, and 61 , describing an older candidate. For education, we also include three possibilities: one describing a candidate with basic education, one with intermediate, and finally one with university level degree. For ideology, we are more interested in the effect of ideological proximity rather than positions on a specific dimension such as left-right or GAL-TAN. We therefore offer two alternatives: either that the candidate is close to own political views or that the candidate is far from ones' own political views. For political experience, we include three alternatives: no current office holding, experience as local councilor or experience as MP. Finally, for the chance of winning seat, we offer three possibilities: unlikely to win seat, intermediate, and likely to win seat.

In conjoint experiments, attribute levels included in each comparison of profiles are randomly selected, and the respondent is asked to select the candidate profile that they prefer. Since each respondent was asked to evaluate seven sets of profiles, all respondents evaluated 14 profiles each. The number of comparisons included in conjoint analyses vary but although the number of comparisons, levels and attributes affect the difficulty of the task, Bansak et al. (2018) show that treatment effects remain stable even with many comparisons and attributes. Hence, there is in

\footnotetext{
${ }^{7}$ This is close to the mean age of the candidates nominated for election over the period 1995-2019, which is 46 years. The average age of nominated and elected candidates in the 2019 election is 47.
} 
practice rarely a specific upper limit to the number of comparisons, but we here limited the number of comparisons to seven for each respondent to avoid satisficing. ${ }^{8}$

For each attribute we include a "NO INFORMATION"9 category and respondents were instructed to interpret this as no information being available, i.e., it was for example unclear whether the candidate was a man or a woman. We use this as the reference category in all analyses, meaning the results reflect the causal effect of revealing a certain candidate characteristic (e.g., being either male or female) compared to this characteristic being unknown. This approach has the advantage of avoiding the problem of selecting a reference category, which in some cases may be quite arbitrary (Leeper et al., 2020), and makes it straightforward to compare the effect sizes across attributes.

Although conjoint experiments have advantages compared to traditional approaches, there are also potential problems. The estimated effects are population averages, which entails that there may be important differences across different subgroups (Abramson et al., 2019; Leeper et al., 2020). For this reason, it is also important to examine differences in effects between subgroups in the population. This is in line with our $\mathrm{H} 2$, where we examine differences across levels of political sophistication, as measured by political interest, discussing politics, internal political efficacy, party identification and voting in previous national election. ${ }^{10}$ Previous research suggests that effects are likely to differ depending on level of sophistication (Popkin and Dimock, 1999). By including different

\footnotetext{
${ }^{8}$ It can be a problem that some combinations of attribute levels may be unrealistic or even logically impossible. Although it is possible to avoid specific combinations to increase authenticity of the comparison (Hainmueller et al., 2014: 20), it is usually preferable to avoid making such restrictions by formulating levels that can be plausibly combined. In this case, even if some combinations are more likely to occur than others, none are logically impossible, and we therefore proceed without making any restrictions on the combinations presented to respondents.

${ }^{9}$ This category is presented in capital letters to highlight the special status of it.

${ }^{10} \mathrm{It}$ is impossible to examine all potential sub-groups in this study. While this did not form part of the pre-registration, we tested whether there were differences in the effects of endorsements across respondents' gender, as suggested by Krupnikov et al. (2020). We did not, however, find any significant differences depending on whether respondents were male or female.
} 
measures of the multifaceted concept of sophistication, we increase the robustness of our results concerning the potential differences between low and high sophisticated voters.

Average marginal component effects (AMCEs) are estimated using OLS linear regression (Hainmueller et al., 2014, 7-9) with standard errors clustered at the respondent level since each respondent makes seven comparisons of candidates. The results are reported with coefficient plots, as recommended by Hainmueller et al. (2014), but the results of all regression analyses are available in the supplement file. The AMCE indicates the average change in the probability that a candidate profile will win support when it includes the listed attribute value instead of the baseline attribute value (here no information provided).

To examine differences across levels of political sophistication, we include interaction effects between the candidate attributes and the measure of sophistication in the models (Hainmueller et al 2014). The result is the Average Component Interaction Effect (ACIE), which makes it possible to examine whether effects differ across groups. When judging the relevance of the interaction effects, we do not only rely on conventional tests of significance, since these are insufficient to certify the importance of the interaction effects (Kam and Franzese, 2007, 43-44). We also consider the practical implications by seeing whether the effects have similar magnitudes and directions for different values of the moderator.

To allow for a complete interpretation of the results, we also calculate marginal means, which describe the level of favorability toward profiles that have a particular feature level, ignoring all other features (Leeper et al., 2020). This is particularly valuable when examining differences across sub-groups of respondents since the choice of reference category may lead to misleading conclusions when examining ACIEs, whereas marginal means are unaffected by this choice (Leeper et al., 2020). 
As political sophistication is a broad concept and cannot be measured with a single indicator, we use several different indicators to measure comprehensively its effects on candidate choice. We examine differences across five different aspects or indicators: political interest, frequency of political discussions, internal political efficacy, party identification, and voting in the last parliamentary election. While important differences exist between these indicators, they all gauge how involved the respondents are to political matters, which is closely related to the concept of political sophistication (Rapeli, 2013, 16).

For political interest, we use a question where we asked respondents about their interest in political matters on a four-fold scale (from "not at all interested" to "very interested"). This was subsequently dichotomized to ease interpretation of results (Low: "Not at all /not very interested" - High: "Somewhat/Very interested"). We measure the frequency of political discussions on a five-fold scale (Never, rarely, sometimes, often, every day). This was also dichotomized (Low: Never/Rarely/Sometimes; High=Often/Everyday). For internal efficacy, we combine answers to two statements "Sometimes politics seems so complicated that I cannot quite understand what is going on" and "I could take an active role in political matters", both scored on a five-point Likert scale (Totally disagree-Totally agree). The two items were combined to an index ranging from $0-8$ where higher scores indicate higher levels of efficacy. This was then divided into three categories: Low efficacy (0-3), Intermediate efficacy (3) and High efficacy (4-8). For party identification, we use a question asking respondents if they feel close to a particular political party (yes/no). Finally, for voting in the general elections we use a question asking respondents whether they voted in the previous 2019 parliamentary elections, where respondents who were uncertain or did not have voting rights were coded as no-voters. Table 2 presents descriptive statistics on the political sophistication variables. 
Table 2. Descriptive statistics

\begin{tabular}{lccc}
\hline Variable & Observations & Mean & SD/SE \\
\hline Political interest (0-3) & 14294 & 1.766 & 0.911 \\
Political interest: Low (0-1) & 5054 & 0.709 & 0.006 \\
Political interest; High (2-3) & 9240 & 2.344 & 0.005 \\
Political discussions (0-4) & 14294 & 2.312 & 1.073 \\
Political discussions: Low frequency (0-2) & 7966 & 1.511 & 0.007 \\
Political discussions: High frequency (3-4) & 6328 & 3.321 & 0.006 \\
Internal efficacy index (0-8) & 14294 & 1.742 \\
Internal efficacy: Low (0-3) & 5026 & 4.066 & 0.014 \\
Internal efficacy: Intermediate (4) & 3836 & 2.214 & 0.000 \\
Internal efficacy: High (5-8) & 5432 & 4.000 & 0.012 \\
Party identification (0/1) & 14294 & 5.825 & 0.496 \\
Party identification: None & 6258 & 0.562 & N/A \\
Party identification: Yes & 8036 & 0.000 & N/A \\
Voted 2019 elections (0/1) & 14294 & 1.000 & N/A \\
Voted 2019 elections: No & 3976 & 0.722 & N/A \\
Voted 2019 elections: Yes & 10318 & 0.000 & 1.000 \\
\hline
\end{tabular}

While we examine what we believe to be important subgroups, it is impossible to examine all potential subgroups and there may be groups of respondents where the reported average effects do not apply. It is therefore also necessary to be careful when interpreting results. It is important to note that a positive AMCE for an attribute level does not imply that the majority of respondents prefer that feature to the baseline (Abramson et al., 2019). Instead, the AMCE indicates a causal effect of an attribute level, not a description of the level of support for a candidate possessing that attribute level (Leeper et al., 2020). For this reason, our results do not entail majority support for any of the candidates, only that candidates who possess certain characteristics find themselves at an advantage or disadvantage compared to a candidate with a slightly different profile.

\section{Empirical analysis}

We start the empirical analysis by presenting the direct effects of all attributes on candidate favorability in Figure 1, which presents both AMCEs and marginal means of all attribute levels. 
Figure 1. Direct effects of conjoint attributes (AMCEs and marginal means).
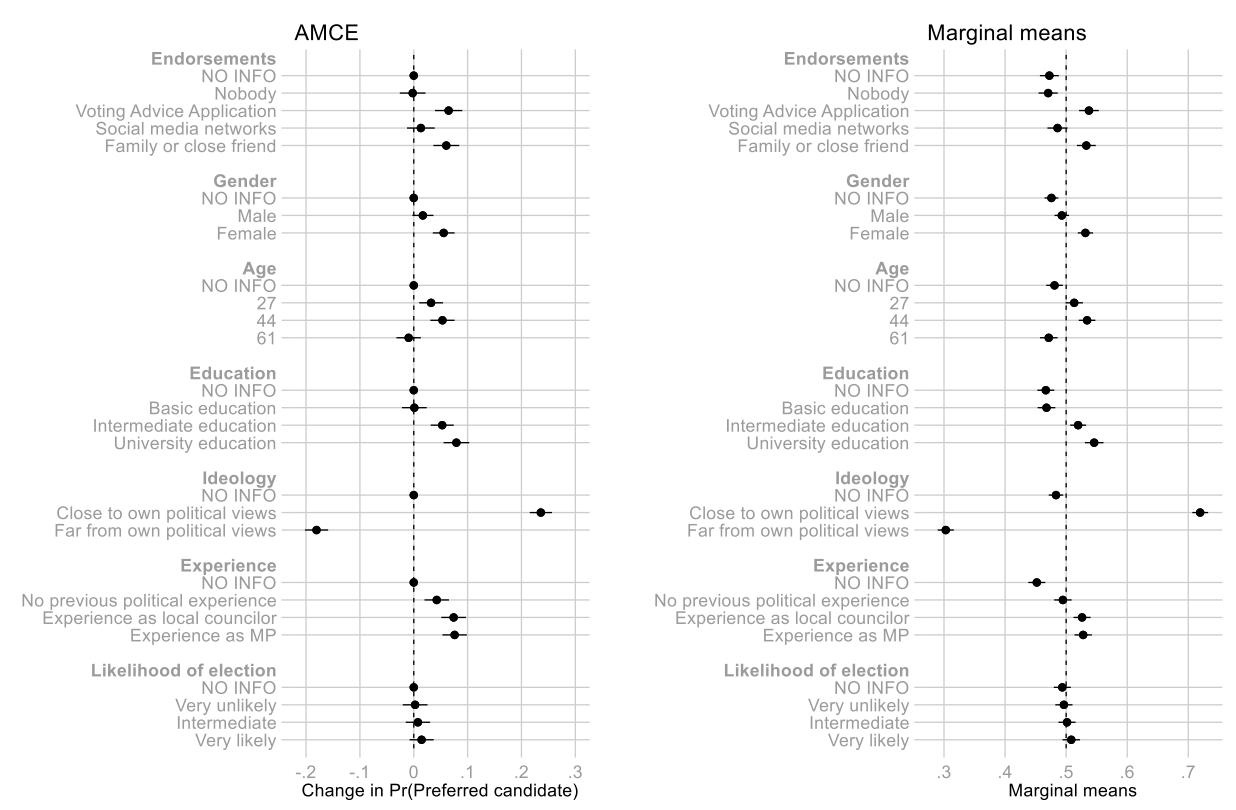

When it is revealed that a candidate was endorsed by a Voting Advice Application (VAA), it has a positive effect on candidate favorability $(B=0.065, p=0.000)$. Hence, this effect entails a 6.5 percentage points increase in favorability, which means that candidates endorsed by VAAs on average had a favorable rating (Marginal mean $=0.537, \mathrm{SE}=0.008$ ). It also has a positive effect when it is revealed that candidates are endorsed by a family member or close friend $(B=0.060, p=0.000)$, which also entails that such candidates on average have favorable rating $(\mathrm{MM}=0.553, \mathrm{SE}=0.08) .{ }^{11}$ Endorsements via social media networks do not seem to have any effect on favorability, however. While the effects of endorsement are small compared to ideological proximity, they are line with the effects of the other attributes included in the conjoint such as gender, educational background and political experience, meaning they should not be dismissed as irrelevant. The results thus partly support $\mathrm{H} 1 \mathrm{a}$ since most endorsements have positive effects on candidate favorability. For H1b, the results are also in line with expectations since the effects from endorsements from social media networks were weak, while endorsements from family and friends had a strong effect. Here it is also

\footnotetext{
${ }^{11}$ While the effects for endorsements from VAAs and family and close friends are significantly stronger than all other categories, the differences between them is not statistically significant (contrast $=-0.004, p=0.736$ ).
} 
worth noting that VAAs had an effect that was at least as strong as the one found for family and friends, which clearly show that these devices provide a new form of endorsements that may rival that of social ties.

While the other attributes are not of central concern for the present purposes, we shortly mention some of the notable results as we can use these results as comparative benchmarks to contextualize the results on endorsement effects. By far the strongest effect comes from ideological proximity, where revealing ideological closeness as expected has a strong positive effect $(B=0.236, p=0.000)$, while ideological distance has a strong negative effect $(-0.181, p=0.000)$. All other effects are of a smaller magnitude, but the effects are nonetheless substantial. Revealing that a candidate is female increases favorability $(B=0.056, p=0.000)$, while the effect for males is also positive, but nonsignificant $(B=0.017, p=0.089) .{ }^{12}$ Candidates who are $27(B=0.032, p=0.004)$ or $44(B=0.053, p=0.000)$ are at an advantage, while it also has positive effects to have an intermediate $(B=0.053, p=0.000)$ and especially university level education $(B=0.079, p=0.000)$. For previous experience, all three levels have positive effects significant at $p=0.000$ (No experience $B=0.043$, Local council $B=0.074$, $M P B=0.076)$, but the marginal means reveal that this is because the no information category is given a negative rating, while it is only those who have experience either from local council or as MP who are given a favorable rating on average by respondents. The likelihood of being elected appears to make very little difference to the respondents when choosing a candidate.

\footnotetext{
12 Using 'Male' as reference category shows that there are also significant differences between male and female candidates $(B=0.039, p=0.000)$.
} 
In order to further explore the effects of endorsements, we also investigate potential indirect effects they might have by moderating the effects of other attributes (Hainmueller et al., 2014). ${ }^{13}$ Figure 2 shows differences in effects depending on what type of endorsement was offered in the conjoint.

Figure 2. Differences in effects of attributes across type of endorsement (ACIEs and marginal means).

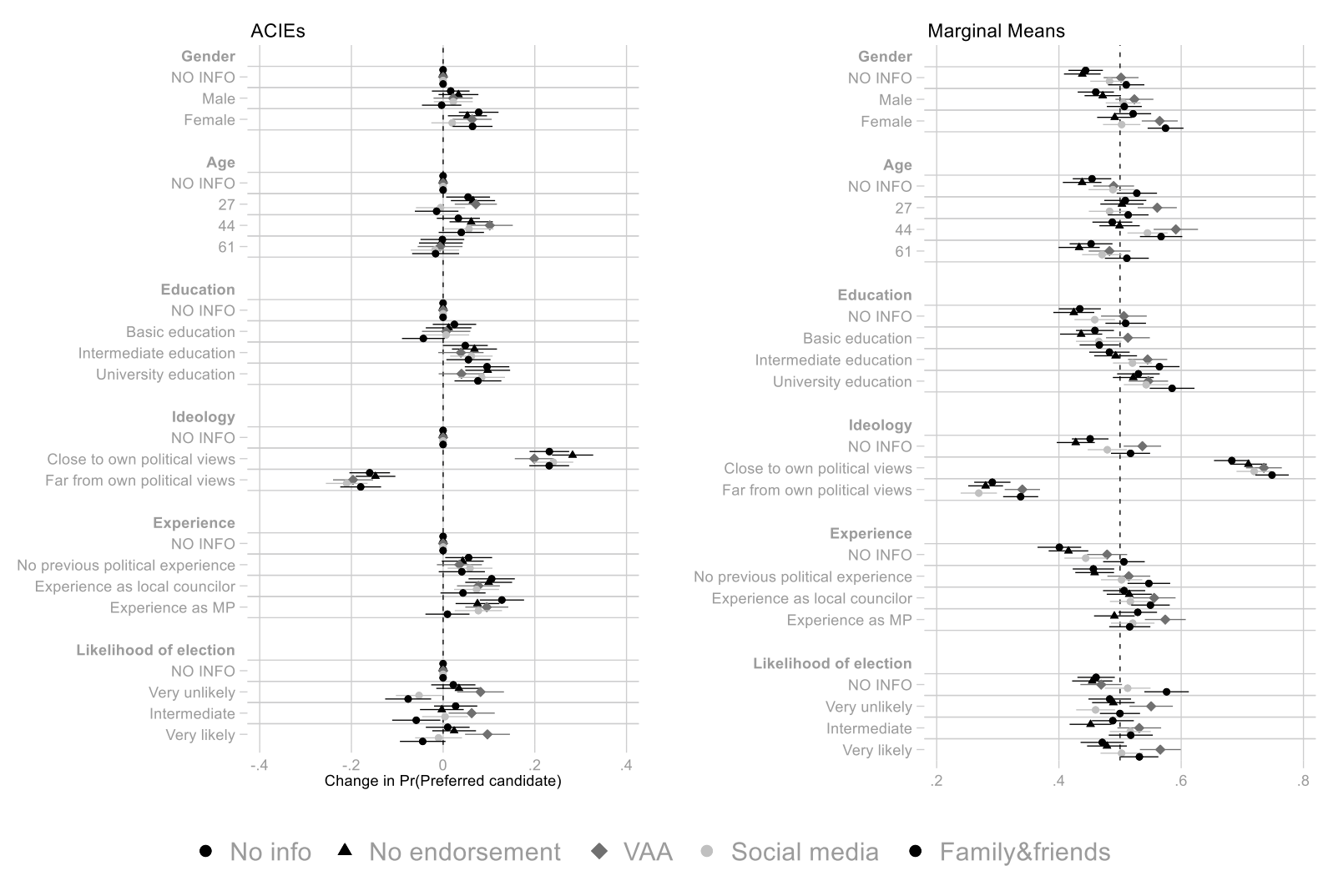

This shows that endorsements can also affect evaluations in an indirect manner, by alleviating potentially damaging effects from other attributes. Since this indirect effect also includes the potentially negative effects of no information, it is necessary to examine the marginal means to realize the implications since relying only on the ACIEs can be misleading (Leeper et al., 2020).

For most attributes, ratings are the lowest for the 'No information' attribute level, especially when the endorsement attribute level is also 'no information' or 'no recommendation' (marked with black

\footnotetext{
${ }^{13}$ This part on indirect effects did not form part of the preregistered plan and we therefore do not offer a specific hypothesis for how recommendations may moderate the effects of other attributes.
} 
circle and black triangle). This is expected since people are likely to be weary of selecting a candidate when they are missing key pieces of information. However, when there are endorsements, especially from either VAAs or family and friends (dark rhombus and light circle), the ratings of the 'no information' attribute levels increase. This shows that endorsements not only have direct positive effects, they also serve as an information proxy when there is no substantial information available.

Next we explore the extent to which the effects of endorsements vary depending on the political sophistication of the respondents, as suggested by our hypothesis $\mathrm{H} 2$. We here examine differences across political interest, discussing politics, internal efficacy, party identification and voting in previous parliamentary elections. Since the results were similar across all indicators, Figure 3 report differences across political interest and discussing politics here, while the rest are in the supplement file.

Figure 3. Differences in effects across level of political interest and frequency of political discussions (ACIEs and marginal means).

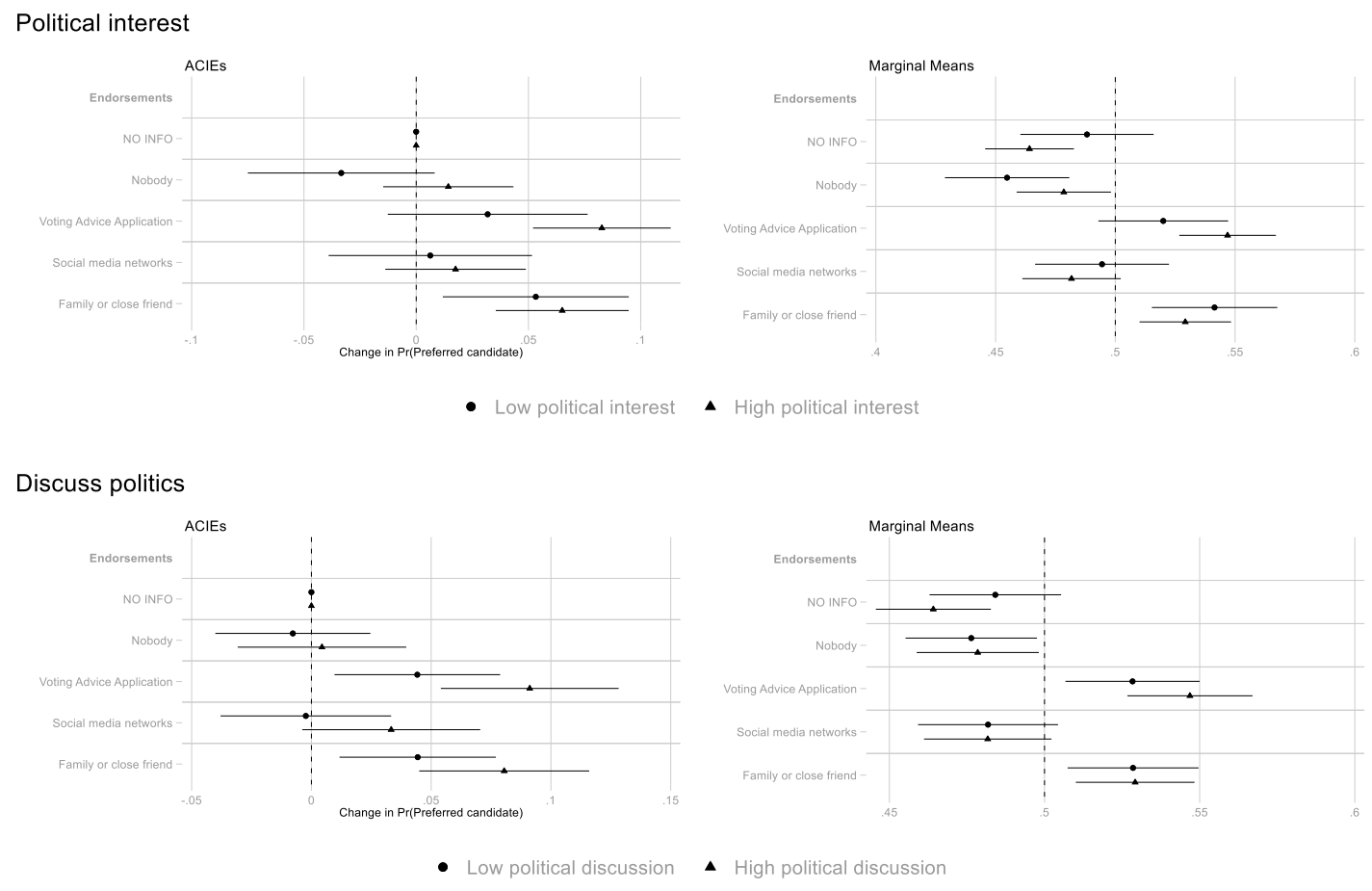


Our hypothesis $\mathrm{H} 2$ suggests that the effects of endorsements should be stronger for those with low political interest. None of the interaction effects are significant at a conventional $p<0.05$ cut off value, but two of them come rather close: the interaction term for the effect of nobody endorses $(B=0.048, p=0.065)$ and for endorsements from VAAs $(B=0.051, p=0.064)$. When scrutinizing the implications in Figure 2, we see that revealing that nobody is endorsing has a small negative effect for those with low political interest $(B=-0.033, p=0.116)$ while it is positive for those with high political interest $(B=0.014, p=0.333)$. Nevertheless, since the effects are in both cases statistically insignificant and rather small, the implications of this are negligible. This conclusion is also supported by the marginal means that show that for both groups, the average mean ratings are below 0.5 when nobody endorses (Low interest=0.45, high interest $=0.48$ ). For VAA endorsements, the implications are greater, since the results suggest revealing this type of endorsement has a positive significant effect among those with high political interest $(B=0.083, p=0.000)$, leading to an increase in favorability of 8.3 percentage points, while it is weaker and insignificant for those with low political interest $(B=0.032, p=0.160)$. For endorsements from social media or family and close friends, the results appear to be identical regardless of the level of political interest, as judged by both significance and implications. All these results then contradict $\mathrm{H} 2$ since it does not appear that endorsements have stronger effects for those with low political interest.

For frequency of political discussion, the expectation based on $\mathrm{H} 2$ is that the effects of endorsements are stronger for those who do discuss politics less often. The pattern resembles the one for political interest. There are no significant interaction effects between endorsements and the frequency of discussing politics as an indicator of political sophistication at a conventional $p<0.05$ level, but the one between VAAs and discussing politics again come fairly close $(B=0.047$, $p=0.069)$. This would mean that VAAs have a stronger effect for people who discuss politics more 
often ( $B=0.091$ compared to $B=0.044)$, which again contradicts $H 2$. As can be seen in the supplement file, the results for internal political efficacy, party identification and voting are even more consistently indicating no differences across levels of political sophistication. All of this leads us to reject $\mathrm{H} 2$ since there is little to suggest that the effects of endorsements differ depending on the respondents' level of political sophistication.

\section{Concluding discussion}

Voters use heuristics when evaluating candidates in elections to simplify their vote choice, but the relative importance and how the process varies across the population remains still unclear. In this study, we have made several contributions to this research agenda by studying how different types of endorsements help voters to select a suitable candidate.

First, we examine how endorsements from three sources affect candidate favorability: Voting Advice Applications (VAAs), social media networks, or family member or close friend. Our results show that endorsements from VAAs and from family and close friends have the expected positive effects on favorability. Furthermore, the effect sizes are in line with known predictors of favorability such as candidate gender, educational attainment, and political experience (Franchino and Zucchini, 2015; Marx and Schumacher, 2018; Ono and Yamada, 2018). The only candidate characteristic that is clearly more important than others is the ideological distance between candidate and respondent, expected considering previous research that shows the strong effects of partisanship (Breitenstein, 2019; Kirkland and Coppock, 2018). We thereby show that endorsements are important to consider for understanding candidate choices.

There are also important differences depending on the source of the endorsements. We hypothesized that the effect of endorsement is related to the strength of social ties between the voter and the source of the endorsement. According to our results, endorsements from family and 
close friends had the strongest effect, which is in line with the idea that social ties matter for the effect of endorsements. Furthermore, endorsements from social media networks did not affect the favorability of candidates, which suggests that social media are less important for determining vote choices than what may be previously thought (Santoro and Beck, 2017). This observation is based on a conjoint experiment, which makes it less likely that it can be dismissed as merely showing that people are unwilling to admit or unaware that social media affect their choices. While we do not claim that the result proves that social media networks are irrelevant for candidate choices, it clearly shows that people are critical of endorsements coming from this channel.

We also find that VAAs clearly influence vote choices, which is in line with previous studies (Munzert and Ramirez Ruiz, 2020). Endorsements of VAAs, based on a matching of issue positions of the voter and the candidates, has an effect on candidate favorability on par with endorsements from family members and close friends. While the connection to social ties is somewhat unclear, VAAs clearly offer a powerful heuristic tool that to some extent can substitute guiding heuristics from social contacts and interactions. It may not be surprising that VAAs are growing in popularity in the highly complex political environment with mandatory preference voting that exist in Finland (Isotalo et al. 2019). Nevertheless, together with the strong effect of ideological proximity, this may be taken as evidence that voters emphasize the substantive side of politics compared to conventional candidate characteristics such as age or gender.

It is also noteworthy that endorsements from VAAs and from family and close friends alleviate the negative effects that it has when key pieces of information are withheld from the voter, such as the candidates' background or ideological proximity. This suggests that a potential causal mechanism for how endorsements affect favorability is that endorsements serve as an information proxy when other information is missing, although more research is needed to establish this conclusively. 
Last, but by no means least, we found nothing to suggest that these effects differed across levels of political sophistication of voters, as suggested by a great deal of research (Bartels, 1996; Popkin, 1991; Popkin and Dimock, 1999; Zaller, 1990). In our study, we found no evidence that endorsements mattered more for those with lower sophistication, whether measured by political interest, frequency of political discussions, internal political efficacy, party identification or voting in previous national election. Some tentative results even indicate that endorsements from VAAs matter more for voters with high levels of political interest and among those that discuss politics frequently. This might be because these groups of voters are more familiar with, and have greater experience of using VAAs in election campaigns (Marschall, 2014). Our results suggests that endorsements in any form are unlikely to help even out the differences between voters with different levels of political sophistication. A possible explanation for this is asymmetric differences between people with low and high political sophistication in the information cues they rely on when deciding how to vote (Sniderman et al., 1991; Cutler, 2002; Kim, 2006; Coffé and von Schoultz, 2020). When voters irrespective of their level of political sophistication use easy heuristics but those with low political sophistication rely only on these easy heuristics, we would not observe systematic differences in effects across level of sophistication. This interpretation is supported by the finding that candidate ideology has a stronger effect on favorability for voters with high political sophistication. As Sniderman and colleagues put it "[...] the better-informed voter tends to take account of nearly everything including the kitchen sink." $(1991,173)$. While our results are hardly conclusive, this suggests a promising avenue for understanding how political sophistication matters for voter behavior.

These results do not come without caveats. The results from conjoint analyses depend on the attributes included (Abramson et al., 2019). While we incorporated attributes commonly found in similar research, it is necessary to ascertain that the results are similar when incorporating other 
aspects of candidate profiles. Furthermore, while we are convinced that the effects are similar across levels of political sophistication, there may be important differences across other sub-groups in the population (Abramson et al., 2019, Leeper et al., 2020). Finally, and perhaps most urgently, it is imperative to examine whether similar effects are found outside of Finland in contexts where voters are used to choosing between candidates when voting. Despite these uncertainties, our results demonstrate that endorsements contribute an important piece of the puzzle when voters decide which candidate to vote for. 


\section{References}

Abramson, Scott F, Korhan Koçak, and Asya Magazinnik. 2019. What Do We Learn About Voter Preferences From Conjoint Experiments? Unpublished manuscript. https://pdfs.semanticscholar.org/023a/24a7dfaddfce626d011596b187f26361ee86.pdf.

Ambady, Nalini, and Robert Rosenthal. 1992. Thin slices of expressive behavior as predictors of interpersonal consequences: A meta-analysis. Psychological bulletin 111(2): 256.

Aldrich, John, Rachel Gibson, and Marta Cantij. 2016. Getting out the vote in the social media era: are digital tools changing the extent, nature and impact of party contacting in elections? Party Politics 22(2): 165-178.

Arnesen, Sveinung, Dominik Duell \& Mikael Poul Johannesson. 2019. Do Citizens Make Inferences From Political Candidate Characteristics When Aiming For Substantive Representation? Electoral Studies 57: 46-60.

Banducci, Susan A., and Jeffrey A. Karp. 2000. Gender, Leadership and choice in multiparty systems. Political Research Quarterly 53(4): 815-848.

Bansak, Kirk, Jens Hainmueller, Daniel J. Hopkins, and Teppei Yamamoto. 2018. The Number of Choice Tasks and Survey Satisficing in Conjoint Experiments. Political Analysis 26 (1): 112-19. https://doi.org/10.1017/pan.2017.40.

Bartels, Larry M. 1996. Uninformed Votes: Information Effects in Presidential Elections. American Journal of Political Science 40(1): 194-194. https://doi.org/10.2307/2111700.

Beck, Paul Allen, Russell J. Dalton, Steven Greene, and Robert Huckfeldt. 2002. The social calculus of voting: Interpersonal, media, and organizational influences on presidential choices. American Political Science Review 96(1): 57-73.

Benjamin, Daniel J., and Jesse M. Shapiro. 2009. Thin-slice forecasts of gubernatorial elections. The review of economics and statistics 91(3): 523-536.

Berelson, Bernard R., Paul F. Lazarsfeld, William N. McPhee, and William N. McPhee. 1954. Voting: A study of opinion formation in a presidential campaign. University of Chicago Press.

Berggren, Niklas, Henrik Jordahl, and Pani Poutvaara. 2010. The Looks of a Winner: Beauty and Electoral Success. Journal of Public Economics 94(1-2): 8-15.

Bernhard, Rachel and Freeder, Sean. 2020. The more you know: Voter heuristics and the information search. Political Behavior 42(2), 603-623.

Bond, Robert M., Christopher J. Fariss, Jason J. Jones, Adam DI Kramer, Cameron Marlow, Jaime E. Settle, and James H. Fowler. 2012. A 61-million-person experiment in social influence and political mobilization. Nature 489(7415): 295-298.

Bond, Robert M., Jaime E. Settle, Christopher J. Fariss, Jason J. Jones, and James H. Fowler. 2017. Social Endorsement Cues and Political Participation, Political Communication, 34(2): 261-281. DOI: 10.1080/10584609.2016.1226223

Breitenstein, Sofia. 2019. Choosing the crook: A conjoint experiment on voting for corrupt politicians. Research \& Politics 6(1): 2053168019832230.

Campbell, Rosie and Philip Cowley. 2014. What Voters Want: Reactions to Candidate Characteristics in a Survey Experiment. Political Studies 62(4): 745-765. 
Carpini, Michael X., and Scott Keeter. 1996. What Americans Know about Politics and Why It Matters. New Haven, CT: Yale University Press.

Coffé, Hilde and Åsa von Schoultz. Forthcoming. How candidate characteristics matter: candidate profiles, political sophistication, and vote choice. Politics.

Converse, Philip E. 1964. The Nature of Belief Systems in Mass Publics. In D. E. Apter (ed.), Ideology and Discontent (pp. 206-261). New York: Free Press.

Conover, Pamela J., and Stanley Feldman. 1986. Emotional Reactions to the Economy: I'm Mad as Hell and I'm not Going to Take it Anymore. American Journal of Political Science 30(1): 50-78.

Cox, Gary W., and Jonathan N. Katz. 1996. Why did the incumbency advantage in US House elections grow?. American Journal of Political Science 40(2): 478-497.

Cutler, Fred. 2002. The Simplest Shortcut of All: Sociodemographic Characteristics and Electoral Choice. Journal of Politics 64(2): 466-490.

Dahl, Robert Alan. 1989. Democracy and Its Critics. Yale University Press.

Dalton, Russell J. 1984. Cognitive Mobilization and Partisan Dealignment in Advanced Industrial Democracies. Journal of Politics 46: 264-284.

Downs, Anthony. 1957. An economic theory of political action in a democracy. Journal of political economy 65(2): 135-150.

Van Erkel, Patrick FA. 2019. Sharing is caring: the role of voter-candidate similarities in intra-party electoral competition. European Political Science Review 11(1): 75-89.

Eulau, Heinz. 1980. The Columbia studies of personal influence: Social network analysis. Social Science History 4(2): 207-228.

Feld, Scott L., and Bernard Grofman. 1991. Incumbency advantage, voter loyalty and the benefit of the doubt. Journal of Theoretical Politics 3(2): 115-137.

Franchino, Fabio, and Francesco Zucchini. 2015. 'Voting in a Multi-Dimensional Space: A Conjoint Analysis Employing Valence and Ideology Attributes of Candidates'. Political Science Research and Methods 3 (2): 221-41. https://doi.org/10.1017/psrm.2014.24.

Funk, Carolyn L. 1997. Implications of Political Expertise in Candidate Trait Evaluations. Political Research Quarterly 50(3): 675-697.

Garzia, Diego and Stefan Marschall. 2012. Voting Advice Applications Under Review: The State of Research. International Journal of Electronic Governance 5(3). DOI: 10.1504/IJEG.2012.051309

Garzia, Diego and Stefan Marschall. 2019. Voting Advice Applications. Oxford research encyclopedia, Politics. DOI: 10.1093/acrefore/9780190228637.013.620

Garzia, Diego., Andrea H. Trechsel \& Alexander De Angelis. 2017. Voting advice applications and electoral participation: A multi-method study. Political Communication, 55, 1-20.

Gemenis, Konstantions \& Rosema, Martin. 2014. Voting advice applications and electoral turnout. Electoral Studies, 36, 281-289.

Goren, Paul. 1997. Political Expertise and Issue Voting in Presidential Elections. Political Research Quarterly, 50(2), 387-412. https://doi.org/10.1177/106591299705000207

Gschwend, Thomas, Michael Stoiber, and Mareen Günther. 2004. Strategic voting in proportional systems: the case of Finland. Mannheim. https://nbn-resolving.org/urn:nbn:de:0168-ssoar$\underline{257735}$ 
Hainmueller, Jens, Daniel J. Hopkins, and Teppei Yamamoto. 2014. Causal Inference in Conjoint Analysis: Understanding Multidimensional Choices via Stated Preference Experiments. Political Analysis 22 (01): 1-30. https://doi.org/10.1093/pan/mpt024.

Hainmueller, Jens, Dominik Hangartner, and Teppei Yamamoto. 2015. Validating Vignette and Conjoint Survey Experiments against Real-World Behavior. Proceedings of the National Academy of Sciences 112 (8): 2395-2400. https://doi.org/10.1073/pnas.1416587112.

Holli, Anne Maria, and Hanna Wass. 2010. Gender-based voting in the parliamentary elections of 2007 in Finland. European Journal of Political Research, 49(5): 598-630.

Huddy, Leonie, Alexa Bankert, and Caitlin Davies. 2018. Expressive versus instrumental partisanship in multiparty European systems. Political Psychology 39: 173-199.

Isotalo, Veikko, Theodora Järvi, and Åsa von Schoultz. 2019. The Finnish Voter 2003-2019. Helsinki: Ministry of Justice.

Johns, Robert and Mark Shephard. 2007. Gender, Candidate Image and Electoral Preference. British Journal of Politics and International Relations 9: 434-460.

Kam, Cindy, and Robert J. Franzese. 2009. Modeling and Interpreting Interactive Hypotheses in Regression Analysis. Ann Arbor: University of Michigan Press.

Kamoen, Naomi, André Krouwel, Bregje Holleman, Jasper van de Pol and Claes de Vreese. 2015. The effect of voting advice applications on political knowledge and vote choice. Irish Political Studies, 30(4), 1-24.

Kim, Do-Kyung. 2006. Political Sophistication and Partisan Cues: Insight from South Korea's 2002 Presidential Election. PhD Dissertation, University of Tennessee.

Kirkland, Patricia A., and Alexander Coppock. 2018. Candidate Choice Without Party Labels. Political Behavior 40(3): 571-91. https://doi.org/10.1007/s11109-017-9414-8.

Kleinnijenhuis, Jan, Jasper van de Pol, Anita van Hoof and André Krouwel. 2017. Genuine effects of vote advice applications on party choice: Filtering out factors that affect both the advice obtained and the vote. Party Politics. doi:10.1177/1354068817713121

Knobloch-Westerwick, Silvia, Nikhil Sharma, Derek L. Hansen, and Scott Alter. 2005. Impact of popularity indications on readers' selective exposure to online news. Journal of broadcasting \& electronic media 49(3): 296-313.

Kristensen, Niels Nørgaard, and Trond Solhaug. 2017. Students as first-time voters: The role of voter advice applications in self-reflection on party choice and political identity." JSSE-Journal of Social Science Education.

Krupnikov, Yanna, Milita, Kerri, Ryan, John Barry \& Connors, Elizabeth C. 2020. How gender affects the efficacy of discussion as an information shortcut. Political Science Research and Methods, 8(2), 268-284.

Latané, Bibb. 1981. The psychology of social impact. American psychologist, 36(4): 343.

Lau, Richard R. and David P. Redlawsk. 2006. How Voters Decide. Information Processing During Election Campaigns. New York, NY: Cambridge University Press.Leeper, Thomas J., Sara B. Hobolt, and James Tilley. 2020. Measuring Subgroup Preferences in Conjoint Experiments. Political Analysis 28 (2): 207-21. https://doi.org/10.1017/pan.2019.30. 
Lerman, Kristina. 2007. Social information processing in news aggregation. IEEE Internet Computing 11(6): 16-28.

Lupia, Arthur. 1994. Shortcuts versus encyclopedias: Information and voting behavior in California insurance reform elections. American Political Science Review, 88(1): 63-76.

Luskin, Robert C. 1990. Explaining political sophistication. Political Behavior, 12(4): 331-361.

Marschall, Stefan. 2014. Profiling users. In Diego Garzia \& Stefan Marschall (eds.), Matching voters with parties and candidates: Voting advice applications in comparative perspective (pp. 93-104). Colchester, U.K.: ECPR Press.

Marx, Paul, and Gijs Schumacher. 2018. Do Poor Citizens Vote for Redistribution, Against Immigration or Against the Establishment? A Conjoint Experiment in Denmark. Scandinavian Political Studies 41(3): 263-282.

McPhee, William N. 1963. Formal Theories of Mass Behavior. New York: Free Press of Glencoe.

Messing, Solomon, and Sean J. Westwood. 2014. Selective exposure in the age of social media: Endorsements trump partisan source affiliation when selecting news online. Communication research 41(8): 1042-1063.

Milic, Thomas. 2020. The use of the endorsement heuristic in Swiss popular votes. Swiss Political Science Review, forthcoming.

Munzert, Simon and Ramirez Ruiz, Sebastian. 2020. Meta-Analysis of the Effects of Voting Advice Applications. Political Communication, forthcoming.

Neuman, W. Russell. 1986. The Paradox of Mass Politics: Knowledge and Opinion in the American Electorate. Cambridge, MA: Harvard University Press.

Nowak, Andrzej, Jacek Szamrej, and Bibb Latané. 1990. From private attitude to public opinion: A dynamic theory of social impact. Psychological review, 97(3), 362.

Nord $\varnothing$, Åsta Dyrnes. 2019. Consistent Citizens? Exploring and Explaining Mechanisms of Opinion Change. University of Bergen.

Ohme, Jakob, Claes H. de Vreese, and Erik Albaek. 2018. The uncertain first-time voter: Effects of political media exposure on young citizens' formation of vote choice in a digital media environment. New Media \& Society, 20(9): 3243-3265.

Ono, Yoshikuni and Masahiro Yamada. 2018. Do voters prefer gender stereotypic candidates? Evidence from a conjoint survey experiment in Japan. Political Science Research and Methods, online first: www.doi.org/10.1017/psrm.2018.41

Page, Benjamin I., and Robert Y. Shapiro. 2010. The Rational Public: Fifty Years of Trends in Americans' Policy Preferences. Chicago: University of Chicago Press.

Pedersen, Rasmus T., Jens Olav Dahlgaard, and Manuele Citi. 2019. Voter Reactions to Candidate Background Characteristics Depend on Candidate Policy Positions. Electoral Studies 61.

Popkin, Samuel L. 1991. The Reasoning Voter. Chicago: University of Chicago Press.

Popkin, Samule L. and Michael A. Dimock. 1999. Political knowledge and citizen competence. In Elkin, S. L. \& Soltan, K. E. (eds.). Citizen competence and democratic institutions, pp. 117-146.

Rapeli, Lauri. 2013. The conception of citizen knowledge in democratic theory. Basingstoke: Palgrave Macmillan. 
Salganik, Matthew J., Dodds, Peter S. and Watts, Duncan J. 2006. Experimental study of inequality and unpredictability in an artificial cultural market. Science, 311: 854-856. doi:10.1126/

science.1121066

Santoro, Lauren Ratliff, and Paul A. Beck. 2017. Social networks and vote choice. The Oxford Handbook of Political Networks, Oxford: Oxford University Press:383-406.

von Schoultz, Åsa. 2018. Electoral Systems in Context: Finland. In Erik S. Herron, Robert J. Pekkanen and Matthew S. Shugart (Eds.) Oxford Handbook of Electoral Systems. Oxford: Oxford University press. Pp. 601-626.

Schultze, Martin. 2014. Effects of voting advice applications (VAAs) on political knowledge about party positions. Policy \& Internet, 6(1): 46-68.

Sinclair, Betsy. 2012. The Social Citizen: Peer Networks and Political Behavior. University of Chicago Press.

Singh, Shane P. and Roy, Jason. 2014. Political knowledge, the decision calculus, and proximity voting. Electoral Studies 34: 89-99.

Sniderman, Paul M., James M. Glaser, and Robert Griffin. 1991. Information and Electoral Choice. In Paul M. Sniderman, Richard A. Brody \& Philip E. Tetlock (Eds.) Reasoning and Choice: Explorations in Political Psychology. Cambridge: Cambridge University Press. Pp. 164-178.

Steffes, Erin M., and Lawrence E. Burgee. 2009. Social ties and online word of mouth. Internet research

Sundar, S. Shyam, and Clifford Nass. 2001. Conceptualizing sources in online news. Journal of communication 51(1): 52-72.Trechsel, Alexander H. and Diego Garzia. 2019. Voting Advice Applications: The Power of Self-Persuasion. In Elizabeth Suhay, Bernard Grofman, \& Alexander H. Trechsel (eds.) The Oxford Handbook of Electoral Persuasion. Oxford Handbooks online. DOI: 10.1093/oxfordhb/9780190860806.013.51

Suomen virallinen tilasto, 2019. Väestö on Tieto- Ja Viestintätekniikan Käyttö [verkkojulkaisu], Tilastokeskus, Helsinki. http://www.stat.fi/til/sutivi/2019/sutivi_2019_2019-1107_kat_002_fi.html (Accessed 29 October 2020).

Walgrave, Stefaan, Peter Van Aelst, and Michiel Nuytemans. 2008. 'Do the vote test': the electoral effects of a popular vote advice application at the 2004 Belgian elections. Acta Politica 43(1): 5070.

Wall, Matthew, André Krouwel, and Thomas Vitiello. 2014. Do voters follow the recommendations of voter advice application websites? A study of the effects of kieskompas.nl on its users' vote choices in the 2010 Dutch legislative elections. Party Politics 20(3): 416-428.

Zaller, John. 1990. Political awareness, elite opinion leadership, and the mass survey response. Social Cognition 8(1): 125-153.

Zaller, John R. 1992. The Nature and Origins of Mass Opinion. Cambridge, Cambridge university press. 